\title{
Promover competências em contexto educativo: estudo de três propostas de intervenção
}

\author{
Promote competencies in an educational context:
} study of three intervention proposals

Maria Isabel Pinto Simões Diasa

\section{Editores}

Maria Inês Côrte Vitoria PUCRS, Brasil

Pricila Kohls dos Santos PUCRS, Brasil

\section{Equipe Editorial}

Carla Spagnolo PUCRS, RS, Brasil

Marcelo Oliveira da Silva PUCRS, RS, Brasil

Rosa Maria Rigo

PUCRS, RS, Brasil

ISSN 2179-8435

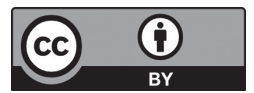

A matéria publicada neste periódico é licenciada sob forma de uma Licença Creative Commons - Atribuição 4.0 Internacional. http://creativecommons.org/licenses/by/4.0/
RESUMO: Este estudo tem como objetivo refletir sobre a promoção de competências em contexto educativo, apresentando três propostas de intervenção psicoeducativa, o Programa Going for the Goal - GOAL (DANISH, MEYER, MASH, HOWARD, CURL, OWENS e KENDALL, 1992), o Programa de Promoção de Competências Sociais (MATOS, SILVA, ALÃO, ALVES, SAMPAIO e CARVALHO, 1997) e o Programa Instrutivo para a Educação e Libertação Emocional - PIELE (HERNÁNDEZ e HERNANDÉZ, 2001). Visando o desenvolvimento pessoal e social dos seus participantes (crianças e jovens), estes programas recorrem a pequenas peças/histórias, à expressão corporal e à dramatização para o ensino/aprendizagem de competências transversais. Assumindo uma metodologia interventiva contextualizada e ativa, defendem o formador como um facilitador das aprendizagens que centra a sua atenção nos sujeitos aprendentes. Tendo sido implementados em contexto educativo nos EUA e na Europa, os dados da avaliação da sua eficácia revelam ganhos ao nível do desenvolvimento de valores prósociais, do bem-estar, da aquisição de comportamentos sociais e da autovalorização. Essas evidências induzemnos a acreditar que serão propostas de promoção de competências a conhecer e a utilizar em contexto educativo. Palavras-chave: Competências. Contexto educativo. Programas de intervenção.

ABSTRACT: This study reflects about competencies promotion in educational context, presenting three proposals for psychoeducational intervention, Going for the Goal (GOAL) Program (DANISH, MEYER, MASH, HOWARD, CURL, OWENS, \& KENDALL, 1992), Social Competencies Promotion Program (MATOS, SILVA, ALÃO, ALVES, SAMPAIO, \& CARVALHO, 1997) and Instructional Program for Education and Emotional Release - PIELE (HERNÁNDEZ, \& HERNÁNDEZ, 2001). These three programs aim personal and social development of the participants (children and youth) and make use of small parts/stories, the body language and drama to the teaching / learning of transversal competencies. Taking a contextualized and active interventional methodology, they defend the teacher as a facilitator of learning that focuses its attention on the learners. Having been implemented in educational settings in U.S. and Europe, assessment data show its effectiveness in the development of pro-social values, well-being, social behaviors and self-worth. These evidences induce us to believe that these programs are good intervention proposals to competencies promotion in educational context. Keywords: Competencies. Educational context. Intervention programs.

a Doutora em Psicologia pela Universidade de Aveiro, Portugal. <isabel.dias@ipleiria.pt>. 
- ste estudo visa refletir sobre a promoção de competências em contexto educativo, apresentando três propostas de intervenção psicoeducativa, (i) o Programa Going for the Goal, de Danish, Meyer, Mash, Howard, Curl, Owens e Kendall (1992), (ii) o Programa de Promoção de Competências Sociais, de Matos, Silva, Alão, Alves, Sampaio e Carvalho (1997) e (iii) o Programa Instrutivo para a Educação e Libertação Emocional, de Hernández e Hernández (2001). De entre várias possibilidades de análise de programas de intervenção ${ }^{1}$, elegemos esses três por se focalizarem no sujeito aprendente e por recorrerem a metodologias ativas de ensino/aprendizagem. Visando a formulação de objetivos, a resolução de problemas ou a comunicação interpessoal, esses três programas pretendem ajudar os participantes a clarificar crenças pessoais e contribuir para uma mudança positiva através da expansão de potencialidades pessoais e sociais. Dirigem-se a estudantes que estão em processo de definição de um projeto de vida, podendo ser dirigidos a outras faixas etárias, desde que realizadas as adaptações convenientes.

Expondo cada um deles, damos a conhecer os seus objetivos e as suas metodologias interventivas, analisando de forma comparativa as suas implicações no âmbito da promoção de competências em contexto educativo.

\section{Promover competências em contexto educativo}

No contexto educativo atual, o termo competência é referenciado com frequência, em âmbitos diversos e com diferentes leituras. Assumindo a competência como a capacidade pessoal de articular/relacionar diferentes saberes/ conhecimentos, atitudes e valores para agir de forma eficaz num determinado tipo de situação (DIAS, 2009), defendemos a possibilidade de promover competências em contexto educativo através de programas de intervenção psicoeducativa, formalmente organizados, sistematizados e teoricamente fundamentados.

De acordo com Matos e Tomé (2012), estes programas de intervenção podem assumir um caráter curativo ou remediativo (focalizados na diminuição de problemas individuais), uma vertente preventiva (impedindo ou dificultando a chegada de determinada condição ou problema) ou desenvolvimental (aprendendo a utilizar competências pessoais e sociais de forma ajustada e adequada ao contexto). Seja numa perspetiva remediativa, preventiva ou desenvolvimental, deseja-se que estes programas sejam adequados às necessidades dos participantes, ao seu nível de desenvolvimento e à sua cultura.

\footnotetext{
1 Por exemplo, Programa "Deusto 14-16", de Pampliega; Pérez, 1997; Programa Crescer a Brincar, de Moreira, 2001; Programa de Desenvolvimento Sócio-Afectivo, de Cruz e Mozaira, 2001; Programa de Refuerzo de las Habilidades Sociales III, de Arándiga e Tortosa, 2003; Programa de Promoção Cognitiva, de Almeida e Morais, 2004 ou Aprender con Autopreguntas - Programa de entrenamiento para alunnos de secundaria, de Sancho e Sánchez, 2006.
} 
Considerando que promover competências através de programas de intervenção permite ao sujeito refletir sobre si e sobre as suas relações com os outros, acreditamos que esta forma de intervenção permite modificar perceções individuais e reforçar comportamentos promotores de bem-estar (DIAS, 2009).

Nos últimos anos, nos Estados Unidos da América e na Europa, têm sido implementados em contexto educativo programas de promoção de competências transversais, conforme os que a seguir se apresentam.

\section{Programa Going for the Goal - GOAL}

O Programa Going for the Goal (GOAL) surgiu nos Estados Unidos da América (Virgínia Commonwealth University), em 1992. Steven Danish, Aleta Meyer, Mark Mash, Catherine Howard, Sherman Curl, Susanna Owens e Kristine Kendall, verificando que os jovens da sua comunidade estavam a assumir comportamentos de risco que poderiam colocar em causa as suas vidas e a vida em comunidade, propuseram-se desenvolver um programa que promovesse a saúde e o desenvolvimento pessoal.

Foi traduzido e adaptado para português por José Cruz, Cláudia Dias, António Rui Gomes, Mariana Cardoso, Daniela Gomes, Helena Oliveira, Manuel Pereira e André Alves, equipa do Instituto de Educação e Psicologia, da Universidade do Minho, em 1998, tendo sido denominado por programa GOAL-Lutar pelos objetivos.

Este programa organiza-se à volta de dois manuais, um para o formador e outro para o(s) estudante(s). O manual do formador apresenta três partes distintas:

a) Descrição sucinta do programa: funcionamento, papel do facilitador das aprendizagens, nome e competências a desenvolver em cada sessão e contrato de compromisso do líder na implementação do programa.

b) Estratégias para liderar o programa: como ensinar competências, como promover a discussão, como coordenar um grupo, como promover a comunicação interpessoal (importância do feedback) e sugestões para a liderança eficaz do programa.

c) Metodologia do programa sessão a sessão: objetivos, revisão dos assuntos discutidos na (última) sessão, exercícios de quebra-gelo, história "O explorador", atividades em grande e pequeno grupo, síntese final.

O manual do estudante é uma compilação de exercícios, um livro de atividades, onde estão incluídas todas as fichas de trabalho que vão sendo realizadas ao longo do programa. Inclui, também, um conjunto de folhas possíveis de retirar do manual para que os estudantes possam realizar as atividades a praticar em casa.

É um programa que tem subjacente pressupostos do modelo comportamentalista e cognitivista, nomeadamente no que respeita aos princípios básicos do comportamento que se denominam por cognitivo-comportamentalistas. 
Tem como destinatários estudantes (crianças e jovens) com problemas comportamentais e com idades entre os 10 e os 14 anos. A intervenção decorre em meio escolar e a administração é feita em grupo, coletivamente.

Os principais objetivos a atingir com o programa GOAL passam por promover o desenvolvimento de competências pessoais e sociais. Visa-se melhorar a resiliência das crianças e jovens para que possam aprender estratégias de planeamento do futuro e para que aprendam a tomar decisões e a recorrer à ajuda dos outros sempre que necessário. Procura-se ensinar o sentido do controle pessoal e confiança no futuro de forma a levar os sujeitos a tomar decisões ajustadas às situações, ensinando-se a cidadania.

Como é defendido por Danish et al. (1996) e Dias (2003), o programa GOAL procura que os estudantes desenvolvam competências comportamentais (por exemplo, aprender a comunicar eficazmente com pais e adultos) e/ou cognitivas (por exemplo, aprender a estabelecer objetivos, a planificar, a tomar decisões, a procurar informações). Propõe-se promover competências pessoais que levem os sujeitos a desenvolver comportamentos de promoção de saúde e/ou resiliências para ultrapassar os efeitos de comportamentos passados comprometedores de saúde. Provoca o autocontrole, a autoconfiança sobre o (seu) futuro e a comunicação entre todos os elementos envolvidos.

Os autores deste programa consideram que os seus conteúdos visam o desenvolvimento de competências de vida, importantes em diferentes cenários da existência da criança/jovem, como a:

(1) identificação de objetivos de vida positivos

(2) importância de nos centrarmos no processo de concretização de objetivos

(3) uso de um modelo geral de resolução de problemas

(4) identificação de comportamentos que podem comprometer a saúde e que podem impedir a obtenção dos objetivos

(5) identificação de comportamentos de promoção de saúde que podem facilitar a concretização dos objetivos

(6) importância de procurar e criar estruturas de apoio social ou a

(7) identificação de formas de transferir estas competências de uma situação ou contexto de vida para outros (DANISH, 1997; DIAS, CRUZ e DANISH, 2001; DIAS, 2003; DIAS e CRUZ, 2007).

Quanto à metodologia, o GOAL desenrola-se ao longo de 10 sessões, nas quais as atividades de caráter essencialmente lúdico irão promover uma reflexão individual sobre como cada qual se vê no mundo, nas suas relações consigo e com os outros. Cada sessão tem uma duração média de sessenta minutos.

Num primeiro encontro, os sujeitos são motivados para a participação no programa e convidados a associar-se ao mesmo. Aceite a proposta, começam as sessões.

Na primeira sessão, faz-se a apresentação de todos os elementos que vão participar e distribui-se o material que vai ser objeto de trabalho ao longo das sessões. Identificam-se "exploradores e destruidores" de objetivos e sonha-se com o futuro. 
Todas as outras sessões começam com uma revisão da sessão anterior. De seguida, lê-se uma pequena peça/história ("O explorador") que introduz o novo material a trabalhar.

$\mathrm{Na}$ última sessão faz-se uma revisão do que os estudantes apreenderam ao longo do programa e procura-se que assumam um compromisso de continuação do trabalho. De acordo com Cruz et al. (1998ab) e Dias, Cruz e Danish (2001), o programa encontra-se assim organizado:

1 a Sessão, "dare to dream" (atreve-te a sonhar). Apresenta-se o programa e os líderes. Os estudantes/participantes discutem a importância dos sonhos e sonham com o seu futuro.

$2^{2}$ - Sessão, "setting goals" (formular objetivos). Nesta sessão os sonhos transformam-se em objetivos. Os estudantes aprendem que um objectivo é definido como um sonho para o qual se tem que trabalhar muito para se atingir. Aprendem a importância de estabelecer objetivos; praticam e reconhecem objetivos que podem concretizar, objetivos positivos, específicos, importantes e controláveis.

3 - Sessão, "making your goal reachable" (tornar o teu sonho alcançável). Definem-se objetivos passíveis de ser alcançados. Os estudantes aplicam o que aprenderam na $2^{\mathrm{a}}$ sessão, definindo um objetivo que possam atingir nos próximos dois meses.

4⿳亠口冖 Sessão, "making a goal ladder" (construir uma escada de objectivos). Planifica-se a prossecução do objetivo estabelecido. Os estudantes aprendem como fazer um plano de forma a atingirem o seu objetivo, identificando todos os passos necessários para o alcançarem e colocando-os em ordem numa escada de objetivos.

5- Sessão, "roadblocks to reaching goals" (identificar obstáculos à concretização de objectivos). Os estudantes aprendem como vários obstáculos (exemplo: abuso de drogas, gravidez na adolescência, violência, abandono escolar e/ou falta de autoconfiança) os podem impedir de atingir os seus objetivos.

6- Sessão, "overcoming roadblocks" (ultrapassar os obstáculos). Os sujeitos aprendem e praticam uma estratégia de resolução de problemas chamada PPAR ( $\mathrm{P}$ = pára e esfria os ânimos; $\mathrm{P}=$ pensa em todas as possibilidades; $\mathrm{A}=$ antecipa as consequências de cada escolha; $\mathrm{R}=$ responde à melhor escolha).

7 - Sessão, "seeking help from others" (procurar ajuda dos outros). Os sujeitos aprendem a importância de procurar apoio social de forma a atingirem os seus objetivos e identificam uma equipa de sonho de dez indivíduos (família, amigos e modelos) que os podem ajudar a atingir os seus objetivos.

8- Sessão, "rebounds and rewards" (ressaltos e recompensas - tentativas para a prossecução dos objectivos). Os estudantes aprendem a fazer ressaltos (tornar a tentar) quando um objetivo ou um passo na escada dos objetivos se torna muito difícil de atingir. Também desenvolvem um plano de recompensa pessoal por estas realizações. 
9ำ Sessão, "identifying and building on your strengths" (identificar e promover qualidades e capacidades). Os estudantes identificam as suas forças pessoais (qualidades/pontos fortes) e as estratégias necessárias para desenvolver as suas competências. Também são questionados sobre uma área em que querem melhorar e são convidados a planificar essa melhoria.

10 a Sessão, "going for your goal" (lutar pelo teu objetivo). Procura-se fazer uma revisão do que foi discutido nas sessões anteriores e levar os estudantes a assumir o compromisso de continuar a praticar as competências desenvolvidas nas sessões. Realiza-se um jogo que proporciona uma oportunidade para os estudantes integrarem e aplicarem a informação recebida nas nove sessões anteriores.

O programa GOAL é um programa aplicado a estudantes mais novos por estudantes/formadores mais velhos selecionados no seio da comunidade local e treinados para esta função (peer leaders). Para o desenvolvimento de uma relação de parceria e de acompanhamento entre pares, os autores sugerem um ratio de 2 estudantes/formadores do Ensino Secundário (estudantes com idades entre os 15 e os 18 anos) para um grupo de 15 estudantes do $2^{\circ}$ e $3^{\text {o }}$ Ciclos do Ensino Básico (estudantes com idades entre os 11 e os 14 anos).

Esses estudantes/formadores terão que ter os requisitos de competências de vida necessários para ter sucesso, a capacidade de se comprometer e conhecimentos para ajudar os outros (DANISH, 1996; DANISH e NELLEN, 1997).

Ao longo das sessões os formadores deverão ganhar o respeito dos estudantes e criar um ambiente agradável à aprendizagem. A comunicação de regras de funcionamento contribuirá para esse ambiente de aprendizagem e, ao mesmo tempo, de diversão, alegria e bem-estar (CRUZ et al., 1998a).

Os estudantes/formadores ajudam os participantes a atingir o seu potencial, a identificar objetivos relacionados com as suas possibilidades; inspiram-lhes confiança para atingirem os objetivos; ensinam-lhes a desenvolver e a implementar um plano para atingirem tais objetivos; encorajam-nos a partilhar o que aprenderam com outros indivíduos da sua comunidade.

Para dinamizar este programa, os estudantes/formadores recebem formação onde desenvolvem competências que os levam a saber:

(1) como ensinar competências a outros (o que requer a definição e a descrição da competência; a compreensão dos motivos/razões subjacentes à aprendizagem da competência e a demonstração/prática da competência); e

(2) como gerir/liderar uma discussão (saber usar/colocar questões abertas; saber utilizar os comentários dos estudantes e reflectir sobre eles e saber usar exemplos pessoais). "Aprendem, assim, a falar em grupo, a organizar uma sessão e/ou palestra, a escutar os outros, a transferir as aprendizagens para outros contextos de vida" (DIAS, 2009, p. 1249). 
O programa GOAL já foi implementado junto de mais de 25.000 adolescentes americanos, australianos, canadianos e neo zelandeses. Os dados da avaliação da sua implementação revelaram ganhos ao nível do desenvolvimento de valores pró-sociais (BRUNELLE; DANISH; FORNERIS, 2007) e do rendimento escolar (DIAS et al., 2001).

Em Portugal, a sua aplicação foi feita junto de trinta e cinco estudantes do Ensino Básico (DIAS, 2003) revelando ganhos ao nível da satisfação pessoal. Em 1996 ganhou o prémio Lela Rowland Prevention Award dado pela Associação Americana de Saúde Mental (National Mental Health Association's), tendo também já sido homenageado pelo Departamento Norte-Americano de Saúde e Serviços Humanos para a Prevenção da Violência (DIAS et al., 2001).

A avaliação faz parte integrante do processo de intervenção e, neste programa, sugere-se uma avaliação contínua, seja através de respostas a tarefas realizadas em cada sessão (por exemplo, identificar pessoas que podem ajudar a resolver problemas) ou em casa (por exemplo, imaginar e registar como se visualizam no futuro).

Ao sonhar com o futuro (sessão 1), ao formular objetivos (sessão 2), ao antecipar problemas (sessão 5) ou ao escolher estratégias de resolução de problemas (sessão 6), os participantes vão apreendendo a informação veiculada no programa de forma contextualizada e ativa. Discutindo os assuntos propostos ao longo das sessões entre pares e com o facilitador das aprendizagens, vão desenvolvendo processos de reflexão, de argumentação, de socialização do pensamento. Em parceria, vão desenvolvendo valores como a cooperação, o respeito, a justiça e/ou a honestidade.

O trabalho de Dias $(2003,2006)$ defende que o estudo da eficácia deste programa de intervenção seja concretizado através da utilização de uma avaliação antes e após a implementação do programa. Sugere a aplicação dos seguintes instrumentos de avaliação:

a) Escala de autoconceito de Piers-Harris (adaptação de Veiga, 1989);

b) Teste sociométrico com critérios de preferência e de rejeição (adaptação de Matos, 1998);

c) Inquérito por questionário aos docentes.

Com estes três instrumentos será possível recolher dados acerca da vida do grupo, do autoconceito dos participantes e da perceção dos professores acerca das competências de vida dos mesmos alunos.

A Escala de Autoconceito de Piers-Harris para crianças (Piers-Harris Children Self Concept Scale) visa uma avaliação do autoconceito através da auto-resposta a 80 itens de resposta $\mathrm{Sim} / \mathrm{Não}$. Na sua versão original apresenta seis fatores: aspeto comportamental; estatuto intelectual e escolar; aparência e atributos físicos; ansiedade; popularidade; satisfação e felicidade (ALBERTO, 1999; VEIGA, 1989).

A avaliação sociométrica realizada através de um sociograma de nomeação, incentiva cada sujeito a exprimir os seus sentimentos relativamente aos seus pares nomeando pelo menos três colegas preferidos e preteridos em função de três critérios: brincar, assistir a um espetáculo e contar um segredo (MATOS, 1998). 
O "Questionário de avaliação de competências dos estudantes" (DIAS, 2003), constituído por um conjunto de 15 questões fechadas e abertas, pretende avaliar a perceção que o professor tem acerca de cada um dos seus alunos relativamente a cada competência contemplada no programa GOAL.

Esta forma de avaliação da eficácia do programa de intervenção solicita a existência de dois grupos (grupo experimental e grupo controlo), de forma a avaliar eventuais ganhos para os participantes no âmbito do desenvolvimento de competências.

\section{Programa de Promoção de Competências Sociais}

O programa de promoção de competências sociais data do ano de 1997. É um projeto da autoria de Ana Silva, António Santinha Duarte Alão, Jorge Alves, Miguel Sampaio e Sónia Carvalho, coordenado por Margarida Matos, da Faculdade de Motricidade Humana da Universidade Técnica de Lisboa (Portugal). Foi editado pelo Ministério da Educação, enquadrado no Programa de Promoção e Educação para a Saúde. De cariz cognitivocomportamental, coloca um especial enfoque no corpo e no movimento enquanto objeto e meio de intervenção na área do comportamento social.

Procurando constituir-se como um instrumento de trabalho para profissionais que lidem com alunos com problemas de comportamento, o seu manual de utilização encontra-se organizado em torno de três grandes tópicos:

Identificação de programas de promoção de competências sociais:

a) Proposta de um programa de promoção de competências sociais: comunicação não-verbal, treino assertivo e resolução de problemas;

b) Avaliação.

Destina-se a crianças nos primeiros anos de escolaridade, jovens do ensino secundário e adolescentes tutelados (meio escolar e institucional), com idades compreendidas entre os 8-10 anos e os 13-15 anos. Preferencialmente, deve ser utilizado com grupos de 10 a 12 elementos. Caso o grupo venha a ser maior, sugere-se a presença de um monitor por cada cinco alunos. No mínimo, os grupos deverão ser assegurados por dois monitores.

Os principais objetivos a atingir com o este programa passam por ajudar crianças e adolescentes a desenvolver capacidades pessoais e relacionais, permitindo a cada indivíduo refletir sobre o modo como se relaciona com os outros, encontrando respostas alternativas adequadas à situação (MATOS, 1997, 1998; MATOS et al., 2000).

Pretende permitir às crianças e jovens conhecer melhor o seu corpo e as suas capacidades relacionais, procurando prevenir problemas de comportamento social. Visa o desenvolvimento de competências que promovam a inserção social, a harmonia com os outros, a cooperação, a comunicação verbal e não-verbal, a identificação e solução de 
problemas, a identificação de diferentes tipos de interação e sua adequação a diferentes situações do quotidiano (MATOS, 2005).

Relativamente aos conteúdos, o programa incide em particular sobre alguns aspectos da comunicação não-verbal (postura, espaço interpessoal, gesticulação, expressão facial, contato visual, aparência física, sorriso e voz), da assertividade (cumprimentar, responder a pedidos difíceis, dar e receber elogios, exprimir desacordo, defender uma opinião, convencer alguém, lidar com a injustiça, lidar com a recusa) e da resolução de problemas sociais (compreender e pensar, procurar alternativas, antecipar consequências, escolher alternativas, aplicação das alternativas escolhidas, avaliação das consequências), no domínio das competências sociais (NOGUEIRA, 2000).

No sentido de desenvolver a comunicação e a resolução de problemas promove a análise dos comportamentos relacionais usuais (nos seus aspectos verbais e não verbais) e a reflexão em grupo sobre as vantagens/inconvenientes de diferentes formas de relacionamento interpessoal e sobre distintas formas de resolução de problemas. Possibilita a aprendizagem de um método de resolução de problemas; a análise e modificação de determinadas cognições associadas a sequências habituais de comportamentos; a manutenção e generalização das aquisições adquiridas ao longo das sessões.

Para promover a assertividade exercita a distinção entre assertivo/inibido/agressivo e entre negociar/combinar/ exprimir uma opinião. Ensina a importância de dizer não e de expressar sentimentos. Identifica estados de tristeza e de nervosismo e encontra estratégias para lidar com as alterações de humor e ansiedade (MATOS, 2005; MATOS et al., 2000).

De acordo com Matos (1997, 1998, 2005), o programa desenrola-se ao longo de 12 sessões com uma duração média de oitenta minutos. Cada sessão contempla momentos de dramatização, diálogo em grupo, resolução de problemas, vivência de situações sociais, jogos de cooperação, retorno à calma/relaxamento, comentário acerca da sessão, indicação de trabalhos de casa.

Focaliza a sua atenção no trabalho de consciencialização corporal e no jogo enquanto espaço de interacção social, de solução de problemas e de regras de funcionamento social. Apresentando um conjunto de situações diversificadas, com objetivos comuns, ajustadas ao grupo-alvo, procura motivar os sujeitos para a participação e continuação no programa.

Através de atividades lúdicas e da reflexão sobre a forma como cada um se relaciona com o mundo físico e social, procura facilitar o reconhecimento das respetivas capacidades e a possibilidade de as aplicar no meio em que vive (escola, casa, comunidade local). As atividades propostas, incluídas em sete situações de trabalho, procuram que os sujeitos experimentem momentos de descontração, bem-estar e alegria: 
1. Comunicação não-verbal: procura-se desenvolver a consciência do corpo e das suas possibilidades expressivas na comunicação interpessoal através de exercícios de consciencialização corporal e de comunicação não-verbal (deslocamentos, equilíbrio, dissociação segmentar, exercícios rítmicos com segmentos corporais).

2. Informação sobre o impacto do programa na sua generalização à vida do dia-a-dia: desenvolvem-se competências de comunicação verbal (ouvir/falar) e de generalização ao quotidiano (verificar as vivências de cada um na realidade). Recorre-se ao diálogo em grupo, incentivando a escuta ativa e a capacidade de expressão verbal.

3. Solução de problemas e gestão de conflitos: desenvolve-se a capacidade de planeamento e de realização em colaboração. Realizam-se exercícios em grupo de identificação de problemas, pesquisa de alternativas e antecipação de consequências, tomada de decisão, passagem à prática.

4. Simulação/dramatização de situações: visa o trabalho sobre o estímulo (compreender a situação, perceção adequada de situações sociais); sobre o processamento (codificação/alternativas) e sobre a resposta (realizar/ utilizar competências sociais básicas). Identificam-se alternativas afirmativas/assertivas, passivas/agressivas e desenvolvem-se competências de percepção, análise e realização, que permitam ao sujeito otimizar o seu relacionamento interpessoal. Realizam-se exercícios de dramatização de soluções relacionais problemáticas relevantes no universo relacional do jovem.

5. Jogo de regras: fomenta-se o respeito pela regra como organizadora do espaço/tempo de um encontro social. Desenvolvem-se competências de relacionamento interpessoal em atividades diversificadas (de caráter lúdico) ou próximas das vivências reais dos sujeitos. Vivenciam-se exercícios de cooperação e jogos coletivos com regras adaptadas (jogos de bola, gincanas, etc).

6. Descontração: procura-se sentir o corpo em tranquilidade, realizando exercícios de descontração, deitados, com ou sem sugestões para descontracção, com ou sem música.

7. Partilha de experiências/trabalho de casa: fomenta-se a generalização do trabalho da sessão à vivência do dia-a-dia. Debate-se sobre os assuntos abordados na sessão e realizam-se exercícios de aplicação na vida quotidiana.

O programa exige que o facilitador das aprendizagens tenha em atenção as caraterísticas dos grupos, o espaço e o material a utilizar (preferencialmente o grupo não deve exceder os 15 elementos, o espaço deve ser amplo, o material adequado); que capte e mantenha a atenção dos participantes, adequando a sua postura ao grupo; que mostre disponibilidade e abertura para as sugestões dos alunos, numa posição de proximidade e de mediador às atividades; que fomente e valorize a reflexão como processo de construção de competências. 
Em Portugal, o programa foi aplicado a jovens sujeitos a medidas tutelares pelo Tribunal de Menores do Sistema de Justiça Português com comportamentos avaliados como desajustados socialmente (MATOS, 1997; MATOS et al., 2000), a crianças do Ensino Básico e a adolescentes do Ensino Secundário integrados em turmas de risco, em escolas do Ensino Regular (MATOS, 1998). No que respeita à avaliação de crianças do Ensino Básico e adolescentes a frequentar o Ensino Secundário, utilizaram-se várias fontes: autoavaliação, avaliação pelos pares, avaliação pelos professores e pela família recorrendo-se a questionários (traduzidos e adaptados à realidade portuguesa) e a sociogramas de nomeação e de classificação.

Relativamente ao estudo com participantes sujeitos a medidas tutelares, a avaliação foi contínua, utilizando diferentes instrumentos (grelha de avaliação diária a ser preenchida pelos técnicos e a autoavaliação dos participantes). No que se refere à autoavaliação, o programa solicita a resposta a questionários antes e depois da aplicação do programa (traduzidos e adaptados à realidade portuguesa) e a avaliação sessão a sessão. Os alunos são convidados a registar o seu comportamento durante a sessão e o seu agrado/desagrado pela mesma, numa escala de 1 (mau) a 3 (bom).

A avaliação deste programa faculta indicadores da aceitação e do impacto que as situações propostas tiveram no grupo. Fornece dados relativos à integração dos conteúdos e da sua transferência para outros contextos do quotidiano dos sujeitos.

A avaliação da eficácia deste programa de intervenção sugere a utilização de instrumentos de medida baseados em critérios comportamentais antes e após a implementação do programa (MATOS, 1998):

a) Escala de Autoconceito de Piers-Harris (adaptação de VEIGA, 1989);

b) Inventário de autoavaliação de dificuldades de comportamento social (MATOS, 1993, baseado no Self Report Questionnaire de Spence, 1980);

c) Questionário de avaliação de progressos (follow-up) (MATOS, 1993);

d) Sociograma de nomeação (adaptação de MATOS, 1993);

e) Sociograma de classificação (adaptação de MATOS, 1993);

f) Inventário de problemas de comportamento social na aula (MATOS, 1993).

Aconselha igualmente uma avaliação complementar através do recurso a uma ficha de caraterização, com base nos registos escolares e informação do professor e a uma avaliação dos progressos do aluno, pelo aluno e pela família. A avaliação deste programa contempla, desta forma, a avaliação inicial, contínua, final e longitudinal, baseada, fundamentalmente, em critérios comportamentais. Os resultados sugerem que o programa produziu um efeito preventivo em termos de comportamentos avaliados como sendo socialmente desajustados. Os participantes relataram ter sido uma experiência enriquecedora e promotora do bem-estar (MATOS, 1993, 1998). 


\section{Programa Instrutivo para a Educação e Libertação Emocional - PIELE}

O programa instrutivo para a educação e libertação emocional (PIELE), é da autoria de Pedro Hernández e M. ${ }^{a}$ Dolores Garcia Hernández, da Universidade de La Laguna (Espanha). Data do ano de 2001. É um programa de cariz cognitivo-motivacional que se desenvolve em situações de ensino/aprendizagem e se fundamenta em critérios e estratégias psicopedagógicas. Destina-se a crianças e jovens (a partir dos 10 anos, mas especialmente a estudantes entre os 10 e os 15 anos), constituindo-se como uma intervenção que decorre em meio escolar, de forma coletiva. O seu objectivo principal é o desenvolvimento afetivo e social de crianças e jovens.

O PIELE pretende potenciar o ajustamento e a socialização pessoal através da promoção de um conceito positivo de si próprio, da capacidade de tolerância e de superação de problemas. Procura o desenvolvimento social através da compreensão, da comunicação e da colaboração com os outros, contribuindo para uma educação integral e preparando o aluno não só para conhecer e pensar, mas também para saber viver. Visa, assim, a promoção do bem-estar e da saúde mental dos participantes. Propõe-se fomentar o autoconceito, reduzir medos, superar tristezas, desenvolver a capacidade para tolerar a frustração e superar problemas, reduzir os sentimentos de culpabilidade geradores de inadaptação, desenvolver competências que fomentem a eficácia na ação, desenvolver atitudes positivas face à aprendizagem, analisar a amizade e as relações com outras pessoas, estudar as relações familiares e o desenvolvimento de atitudes de compreensão, autonomia e ajuda à família.

O PIELE contempla o estudo de variáveis cognitivas, afetivas e comportamentais que conduzem a comportamentos de inibição, medo ou de frustração. Preocupa-se com variáveis que promovem o desenvolvimento de comportamentos de autoafirmação, aceitação da realidade e superação de dificuldades. Reflete sobre rotinas e estratégias promotoras de eficácia académica e a sua relação com a satisfação pessoal. Procura o estabelecimento de relações positivas entre pares e equaciona a família como meio para desenvolver e exercitar atitudes de compreensão, autonomia e ajuda.

Neste programa, o facilitador das aprendizagens conhece e compreende as bases teóricas do programa, do seu conteúdo e da sua metodologia:

(1) Conhece os pressupostos teóricos do desajustamento social e dos modelos de intervenção;

(2) Conhece em profundidade cada um dos temas a abordar no programa;

(3) Domina os processos de intervenção grupal e as dinâmicas do grupo;

(4) Cria um clima de seriedade, de intimidade e confiança no grupo de trabalho, despertando o interesse dos participantes;

(5) Adota uma postura de flexibilidade, abertura e reflexão;

(6) Acredita na eficácia do programa, interiorizando-o e participando ativamente nas atividades; 
(7) Acredita no seu potencial enquanto formador e nas possibilidades do contexto para a eficácia do programa.

No que diz respeito à metodologia, o programa é constituído por treze unidades, podendo cada uma ser desenvolvida numa ou mais sessões, atendendo ao tempo disponível e ao ritmo do grupo. A duração de cada sessão é, pois, variável, devendo ser adaptada às circunstâncias concretas em que se aplica.

As unidades instrutivas que constituem o programa são:

(1) Introdução: em busca do tesouro;

(2) Os medos;

(3) O autoconceito;

(4) O que nos põe tristes;

(5) Tolerância à frustração;

(6) Superação de problemas;

(7) A culpabilidade;

(8) Como fazer melhor;

(9) Atitude positiva face à aprendizagem;

(10) Como tirar proveito do estudo;

(11) A amizade e as relações com as outras pessoas;

(12) A família: a relação com os meus pais;

(13) Revisão do trabalho e plano para o futuro.

Estas unidades estão divididas em seções que devem focar as ideias principais, a narração, a elaboração por escrito e a discussão. As atividades propostas passam, assim, por leitura (silenciosa ou em voz alta), respostas escritas, discussão em grupo, psicodrama e exemplificação e realização de compromissos.

As seções correspondem a objetivos específicos que se apoiam em princípios e estratégias psicoeducativas, facilitando a sociabilidade didática, a aprendizagem construtivista e cooperativa, a implicação motivacional e a autorregulação da mudança. Desta forma, o programa apresenta uma sequência clara de atuação, possibilitando aos estudantes ter acesso aos conteúdos de forma estruturada e através de canais distintos.

O Programa Instrutivo para a Educação e Libertação Emocional foi aplicado pelos autores a duas turmas do $6^{\mathrm{O}}$ ano do Ensino Básico (num total de 70 alunos). Implementaram o programa junto de três grupos de estudantes, diferenciando apenas o tipo de linguagem aplicado: direto ou literal, figurado ou metafórico e misto (direto e figurado). Foi também aplicado a 159 estudantes pertencentes a 6 turmas do 6으o ano do Ensino Básico que foram distribuídos em três grupos equiparados quanto ao nível inteletual e ao nível de adaptação. O grupo I recebeu o programa PIELE em linguagem direta, o grupo II em linguagem figurada e o grupo III recebeu um programa placebo. 
A avaliação da eficácia deste tipo de programa instrutivo-emocional foi verificada em várias investigações quasi-experimentais com recurso a análises antes e depois da intervenção. Os itens avaliados contemplavam as mudanças obtidas em fatores de adaptação pessoal e social, as valorizações dos próprios sujeitos e dos responsáveis pelo programa (HERNÁNDEZ; HERNÁNDEZ, 2001).

No estudo inicial com 70 estudantes, os resultados da aplicação do PIELE indicaram uma melhoria significativa depois da sua aplicação na adaptação dos sujeitos aos três tipos de linguagem. No grupo controlo não se verificaram mudanças significativas. No estudo com 159 alunos pertencentes a 6 turmas do $6^{\circ}$ ano do Ensino Básico, os resultados mostraram que os grupos que tinham participado no PIELE, tanto em linguagem direta como em linguagem figurada, apresentavam, depois da intervenção, melhor ajustamento pessoal e social do que os que receberam o programa placebo. Não apareceram diferenças significativas entre os alunos que receberam o PIELE em linguagem direta e os que o fizeram em linguagem figurada. Nesta investigação, os autores registaram persistência das melhorias obtidas, passados oito meses e comprovaram a eficácia do feedback para reduzir a inadaptação pessoal e social e constataram a maior eficácia do professor sobre o psicólogo na administração do PIELE.

\section{Programas de intervenção: análise comparativa}

Refletindo sobre os três programas previamente apresentados (Programa GOAL, Programa de Promoção de Competências Sociais e Programa PIELE), inferimos que o objetivo geral subjacente a cada um deles é o mesmo: promover o desenvolvimento de competências pessoais e sociais em contexto educativo e fomentar o bem-estar.

Situando os programas no seu contexto de realização (EUA e Europa), aferimos que o Programa GOAL (EUA) e o Programa de Promoção de Competências Sociais (Europa) nasceram por se constatar que havia crianças e jovens com poucas oportunidades contextuais para aprender competências de vida, colocando, por isso, em risco a sua permanência na escola e a construção de uma cidadania ativa - surgiram num contexto de (re)aprendizagem de competências de vida para um processo de (re)construção da cidadania. O Programa PIELE (Europa), por sua vez, ergue-se sob a égide do desenvolvimento emocional para o bem-estar pessoal, numa lógica desenvolvimental.

Apresentando um conjunto de propostas formativas diferenciadas, os três defendem uma aplicação em grupo de pares, numa lógica de intervenção cognitivo-comportamental (Programa GOAL e Programa de Promoção de Competências Sociais) ou cognitivo-motivacional (Programa PIELE). Ao longo de 10 (Programa GOAL), 12 (Programa de Promoção de Competências Sociais) ou 13 sessões (Programa PIELE), esses programas destinam-se a crianças e jovens (entre os 8 e os 15 anos). 
Defendendo o recurso a metodologias contextualizadas e ativas de ensino/aprendizagem, os três programas assumem o formador como um orientador/facilitador. Centram-se nos sujeitos aprendentes, solicitando a sua ação e reflexão no desenvolvimento/aprendizagem de competências transversais como a comunicação interpessoal, a formulação de objetivos, o planeamento, o autoconceito ou a resolução de problemas. Através do recurso a pequenas peças/histórias (Programa GOAL), à expressão corporal e à utilização do jogo (Programa de Promoção de Competências Sociais) ou à dramatização e ao diálogo em grupo (Programa PIELE), os três programas fomentam a aprendizagem do pensar sobre a realidade e do saber viver em contexto, em interação com pares e adultos. Em ação colaborativa, os sujeitos aprendentes têm oportunidade de (i) realizar exercícios lúdicos que os levam a aprender a sonhar, a identificar capacidades pessoais ou a procurar a ajuda de outros (Programa GOAL), (ii) desenvolver capacidades relacionais indutoras de comportamentos promotores de saúde (Programa de Promoção de Competências Sociais), (iii) vivenciar situações concretas de medo, frustração e inibição que aprendem a questionar e a resolver (Programa PIELE).

Para os autores destes programas, a tarefa de avaliação de competências e da eficácia da intervenção revela-se complexa, multifacetada e multivariada. Reclama vários instrumentos e momentos de avaliação que só serão possíveis de implementar com eficácia se se conseguir criar um clima de confiança recíproca, de respeito mútuo, reciprocidade e empatia entre facilitador das aprendizagens e participantes. A construção desta relação revela-se essencial no envolvimento dos participantes no processo de implementação e de avaliação dos programas.

Para além de avaliação dos processos de desenvolvimento de competências através de uma apreciação constante, contínua, contextualizada, coletiva, coparticipada, co construída, há que equacionar uma avaliação da eficácia dos programas de intervenção (essencial na reflexão do desenvolvimento de processos individuais e/ou de grupo e na análise de resultados oriundos da vivência de um programa de intervenção).

Partindo-se do pressuposto que os programas de intervenção são eficientes, que favorecem as competências que se propõem desenvolver, há que os validar com rigor, coerência e consistência. Neste sentido, a proposta de validação estatística sugere a utilização de distintos momentos de avaliação (ex-ante e ex-post) e de diferentes grupos (grupo experimental e grupo de controlo). Esta opção fundamenta a escolha criteriosa de instrumentos de avaliação e dos sujeitos de investigação-ação.

Os resultados de avaliação dos programas supra citados revelaram ganhos ao nível do desenvolvimento de valores pró-sociais, da satisfação e do rendimento escolar (Programa GOAL), ao nível da aquisição de comportamentos sociais e do bem-estar (Programa de Promoção de Competências Sociais) e ao nível da adaptação pessoal e social e da auto valorização (Programa PIELE). 
Estes dados permitem-nos inferir o papel significativo que estes programas de intervenção psicoeducativa poderão ter na promoção de competências em contexto educativo. Através de propostas contextualizadas, lúdicas e envolventes, crianças e jovens podem desenvolver/aprender a gerir os seus recursos pessoais e sociais, cimentando perceções individuais e reforçando comportamentos promotores de bem-estar e de integração social.

\section{Considerações finais}

Os dados do Programa Going for the Goal - GOAL (DANISH et al., 1992), do Programa de Promoção de Competências Sociais (MATOS et al., 1997) e do Programa Instrutivo para a Educação e Libertação Emocional PIELE (HERNÁNDEZ; HERNANDÉZ, 2001) permitem-nos refletir sobre a promoção de competências em contexto educativo, revelando ser possível e eficaz a implementação de programas de intervenção psiceducativa de cariz remediativo e/ou preventiva. Revelando ser possível promover o desenvolvimento de competências transversais através de programas formais, teórica e metodologicamente fundamentados e avaliados, os programas supra mencionados mostram a potencialidade das suas propostas na aquisição ou optimização de competências pessoais e sociais levando-nos a acreditar que serão propostas psicopedagógicas a conhecer e a utilizar em intervenções educativas com crianças e jovens.

\section{Referências}

ALBERTO, Isabel. Avaliação da perturbação pós-stress traumático (PTSD) e suas consequências psicológicas em crianças e adolescentes vítimas de mau trato. 1999. Tese (Doutoramento em Psicologia - Avaliação Psicológica) - Faculdade de Psicologia e Ciências da Educação, Universidade de Coimbra, Coimbra, 2011.

ALMEIDA, Leandro; MORAIS, Fátima. Programa Promoção Cognitiva. Braga: Psiquilibros Edições, 2004.

ARÁNDIGA, Antonio; TORTOSA; Consol. Programa de refuerzo de las habilidades sociales III. Madrid: EOS Gabinete de Orientación, 2003.

BRUNELLE, Jaime; DANISH, Steven; FORNERIS, Tanya. The impact of a sport-based life skill program on adolescent prosocial values. Applied Development Sciences, v. 11, n. 1, p. 43-55, 2007.

CRUZ, José; DIAS, Cláudia; GOMES, Rui; CARDOSO, Mariana; GOMES, Daniela; OLIVEIRA, Helena; PEREIRA, Manuel; ALVES, André. Lutar por objectivos: manual do formador. Braga: Universidade do Minho, 1998a.

CRUZ, José; DIAS, Cláudia; GOMES, Rui; CARDOSO, Mariana; GOMES, Daniela; OLIVEIRA, Helena; PEREIRA, Manuel; ALVES, André. Lutar por objectivos: manual do estudante. Braga: Universidade do Minho, 1998b. 
CRUZ, Maria; MAZAIRA, Maria. DAS - Programa de Desenvolvimento Sócio-afectivo. Vila Nova de Gaia: Edipsico, 2001.

DANISH, Steven. Going for the goal: a life skills program for adolescents. In: ALBEE, G.; GULLOTTA, T. (Ed.). Primary prevention works. London: Sage Publications, Inc., 1997. Vol. 6. p. 291-312.

DANISH, Steven. Interventions for enhancing adolescents' life skills. The Human Psychologist, v. 24, p. 365-381, 1996.

DANISH, Steven; MASH, Mark; HOWARD, Catherine; CURL, Sherman; MEYER, Aleta; OWENS, Susanna; KENDALL, Kristine. Going for the goal leader manual. Virginia: Virginia Commonwealth University, Department of Psychology, $1992 \mathrm{a}$.

DANISH, Steven; MASH, Mark; HOWARD, Catherine; CURL, Sherman; MEYER, Aleta; OWENS, Susanna; KENDALL, Kristine. Going for the goal student activity manual. Virginia: Virginia Commonwealth University, Department of Psychology, $1992 \mathrm{~b}$.

DANISH, Steven; NELLEN, Valerie; OWENS, Susanna. Teaching life skills through sport: Community - based programs for adolescents. In: VAn RAALTE, J. L; BREWER, B. W. (Ed.). Exploring Sport and Exercise Psychology. Washington DC: American Psychological Association, 1996. p. 205-224.

DANISH, Steven; NELLEN, Valerie. New roles for sport psychologists: teaching life skills through sport to at-risk youth. Quest, v. 49, p. 100-113, 1997.

DIAS, Cláudia; CRUZ, José; DANISH, Steven. O desporto como contexto para a aprendizagem e ensino de competências de vida: programas de intervenção para crianças e adolescentes. Análise Psicológica, v. XIX, n. 1, p. 157-170, 2001.

DIAS, Isabel. Promoção de competências em educação. Leiria: INDEA-Instituto de Investigação, Desenvolvimento e Estudos Avançados e Instituto Politécnico de Leiria, 2009.

DIAS, Isabel. Programa GOAL: lutar pelos objectivos na adolescência. In: Experiências e intervenções em psicologia da saúde. Algarve: Edições Centro Universitário de Investigação em Psicologia, fev. 2009. p. 1244-1250.

DIAS, Isabel. Promoção de competências pessoais e sociais - o exemplo do Programa GOAL. In: Actas do VII COLÓQUIO SOBRE QUESTÕES CURRICULARES (III COLÓQUI LUSO-BRASIEIRO), 2006. Braga: Centro de Investigação em Educação (CIEd)/ Instituto de Educação e Psicologia da Universidade do Minho, 2006. p. 936-948.

DIAS, Isabel. Programa Going for the goal/“'Lutar pelos objectivos" - um programa de competências de vida aplicado a crianças do $4^{\mathrm{O}}$ ano de escolaridade. Tese (Mestrado em Psicologia) - Faculdade de Psicologia e Ciências da Educação, Universidade de Coimbra, 2003.

DIAS, Isabel; CRUZ, José. Programa Goal: Going for the goal/Lutar por objectivos: um programa de competências de vida no ensino básico. In: Actas da CONFERÊNCIA INTERNACIONAL DE PSICOLOGIA DO DESPORTO \& EXERCÍCIO, 2007. Braga: Universidade do Minho, 2007. p. 125-133.

HERNÁNDEZ, Pedro; HERNÁNDEZ, Maria Dolores. PIELE - Programa Instrutivo para a Educação e Libertação Emocional. Lisboa: CEGOC-TEA, 2001.

MATOS, Margarida. Comunicação, gestão de conflitos e saúde na escola. Lisboa: Faculdade de Motricidade Humana Edições, 2005. MATOS, Margarida. Comunicação e gestão de conflitos na escola. Lisboa: Faculdade de Motricidade Humana Edições, 1998. 
MATOS, Margarida (Coord.). Programa de promoção de competências sociais: manual de utilização. Lisboa: PPES-Ministério da Educação, 1997.

MATOS, Margarida. Perturbações do comportamento social. 1993. Tese (Doutoramento em Necessidades Especiais e Reabilitação)

- Faculdade de Motricidade Humana, Universidade de Lisboa, Lisboa, 1993.

MATOS, Margarida; SIMÕES, Celeste; CARVALHOSA, Susana. Desenvolvimento de competências de vida na prevenção do desajustamento social. Faculdade de Motricidade Humana/Instituto de Reinserção Social-Ministério da Justiça, 2000.

MATOS, Margarida; TOMÉ, Gina (Org.). Aventura Social: promoção de competências e do capital social para o empreendedorismo com saúde na escola e na comunidade. Lisboa: Placebo, 2012.

MOREIRA, Paulo. Crescer a brincar. Coimbra: Quarteto, 2001.

NOGUEIRA, Sara. As relações recíprocas de amizade como factor de desenvolvimento sócio-cognitivo: a competência social em crianças do 4ํano de escolaridade. 2000. Tese (Doutorado em Psicologia do Desenvolvimento) - Faculdade de Psicologia e Ciências da Educação, Universidade de Coimbra, Coimbra, 2000.

PAMPLIEGA, Ana; PÉREZ, Manuel. Programa "Deusto 14-16": desarollo de habilidades sociales. Bilbau: Mensajero, 1997.

SANCHO, Javier; SÁNCHEZ, José. Aprender con autoperguntas. Programa de entrenamiento para alunnos de secundaria. Madrid: CEPE, 2006.

VEIGA, Feliciano. Escala de autoconceito: adaptação portuguesa do Piers - Harris Children's Self-Concept Scale. Psicologia, v. VII, n. 3, p. 275-284, 1989.

\section{Endereço para correspondência:}

Maria Isabel Pinto Simões Dias

Escola Superior de Educação e Ciências Sociais - Campus 1

Rua Dr. João Soares Apartado, 4045

2411-901 Leiria, Portugal

E-mail: <isabel.dias@ipleiria.pt>

Recebido em: fevereiro/2014

Aceito em: maio/2014 